LVCENTVM, IX-X, 1990-91

\title{
PANES, HOGAZAS Y FOGONES PORTÁTILES. DOS FORMAS CERÁMICAS DESTINADAS A LA COCCIÓN DEL PAN EN AL-ANDALUS: EL HORNILLO (TANNŨR) Y EL PLATO ( ȚÄBAG)
}

\author{
SONIA GUTIÉRREZ LLORET \\ Universidad de Alicante
}

\begin{abstract}
En este trabajo pretendemos identificar diversos repertorios cerámicos aparecidos en contextos arqueológicos altomedievales rurales del levante peninsular, con dos sistemas portátiles de coción del pan - el hornillo o tannūr y el plato o tābaq - mencionados en las fuentes literarias árabes, relacionándolos, en algunos casos, con objetos similares mencionados en las fuentes latinas y visigodas. Estudiamos también sus orígenes y perduraciones, pero mientras que el plato figura en las tradiciones tardorromanas de panificación, el hornillo, de tradición semita, parece ser introducido en al-Andalus con la conquista islámica.
\end{abstract}

With this work we want to identify several pottery's series found in rural archaeological sequences of the Middle Ages beginning from the Eastern part of the Iberian Peninsula with two portable methode for bread-baking - the portable furnace or tannür and the baking-plate or tābaq- cited in the literary Arabian sources, contrasting with similar objects quoted by Latin and visigothics sources. This study includes also their origin and perdurance but, whereas these baking-plate appear in the Late Roman baking technology, the portable furnace was, apparently, introduced in al-Andalus with the Islamic conquest.

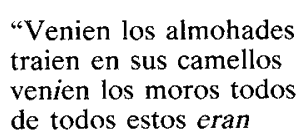

Poema de Fernán González (IX, 387) e los avenmarinos: sus fornos e molinos; de Oriente vezinos, cobiertos los caminos." de todos estos eran
Los criterios habituales de estudio del hecho cerámico - uno de los documentos privilegiados del registro material de una formación social histórica, por su frecuencia de aparición y su carácter perdurable (BAZZANA, 1979 y COLL, 1988-89) - han venido limitándose a establecer una taxonomía morfológica, es decir, una clasificación en categorías de los grupos cerámicos según sus atributos formales. No obstante, en el ámbito de la cerámica medieval $\mathrm{y}$ a tenor posiblemente de su reciente nacimiento como parte de la arqueología histórica, ha habido una preocupación por aunar los criterios morfológicos con los de uso, definiéndose de esta forma series funcionales y tipos específicos dentro de dichas series (ROSELLO, 1978 y BAZZANA, 1979). Paralelamente, la arqueología de las últimas décadas ha vuelto a tomar en consideración los préstamos teóricos de la antropología cultural para estudiar sociedades 
del pasado, comenzando, de esta forma, a definirse la etnoarqueología como la disciplina que, a partir del estudio etnográfico de grupos sociales tradicionales, permite construir modelos y proponer explicaciones aplicables al estudio arqueológico de sociedades desaparecidas. Con todas las precauciones lógicas -es a todas luces obvio el peligro que entrañan las analogías mecanicistas - creemos posible que el estudio etnográfico de algunos aspectos, como el de las técnicas materiales y los instrumentos de trabajo, pueda arrojar luz sobre determinados hechos arqueológicos de difícil interpretación desde otras perspectivas.

El cada vez mayor conocimiento de los repertorios tipológicos de los asentamientos altomedievales ha permitido comenzar a individualizar deteminados útiles cerámicos relacionados con un aspecto fundamental en los hábitos alimenticios de una comunidad: la transformación y consumo de cereales, en suma, la panificación. La importancia del cereal en la alimentación es obvia, siendo necesario para facilitar su consumo la transformación del grano duro, mediante la molienda, en sémola o harina. Estas permiten el consumo directo en forma de gachas, sopas o pastas - como eran el puls o pulmentum romano (LLOBREGAT, 1989b) o la harisa musulmana (LEVI-PROVENÇAL, 1987, 272 y ss.) - pero presentan el inconveniente de su carácter perecedero. Sin embargo, el mero hecho de someter la pasta a un proceso de cocción por calor, o lo que es lo mismo, la fabricación de pan, garantiza una mayor capacidad de asimilación nutritiva, permite la conservación del cereal durante más tiempo y ofrece la posibilidad de su rehidratación en otras formas de consumo (CINTAS, 1962, n.16). Es más, en algunas poblaciones rurales de Argelia, la dieta de alimentación tradicional se caracteriza, frente a una malnutrición proteica de origen animal, por una preponderancia casi absoluta de cereales consumidos en forma de torta de pan o de sémola cocida al vapor (S.V. A164 «Alimentation». ENCYCLOPÉDIE BERBÈRE, 1987. Demoulin y chamla, 495).

No sólo permiten la obtención de harinas panificables el trigo y la cebada, que constituyen la materia prima fundamental para la elaboración del «pan cotidiano». También han sido siempre utilizados a modo de pan de sustitución otros cereales como el arroz, el panizo, el mijo, el sorgo, e incluso se ha usado sucedáneos como la harina obtenida a partir de las leguminosas y frutos secos molidos (la bellota, la algarroba, la castaña o los dátiles secos, entre otros) (GARCIA SANCHEZ, 1988, 525). En este sentido, es particularmente interesante el tratado de agricultura de Ibn al-'Awwām, autor sevillano que escribió a finales del siglo XII (BANQUERI, 1988; facs. 1802) y que recoge, al describir las diversas especies cultivadas, aquellas que son panificables. Sorprende que prácticamente todas las legumbres y gran parte de verduras como los guisantes, habas, lentejas, garbanzos, altramuces, tallos de acelga, zanahorias, ajos, etc., pueden, una vez secos y molidos, proporcionar harinas panificables, si bien mezcladas con otras de mejor calidad. Incluso llega a proporcionar recetas para ablandar cuescos, simientes y raíces de árboles y hortalizas silvestres a fin de obtener pan en épocas de hambre y necesidad. Se trata de lo que Lucie Bolens ha dado en llamar «pan de escasez», que reaparece cada vez que se rompe el equilibrio alimentario por razones militares, económicas o ecológicas, vinculado a una economía basada en la recolección de tipo protohistórico (BOLENS, 1980, 164-71). La necesidad de convertir en pan todo grano feculento o todo vegetal con cierto valor nutritivo, incluso cuando son susceptibles de ser asimilados de otra forma por el organismo, como es el caso de legumbres o verduras, indica, además de la necesidad biológica de alimentación en épocas de hambrunas, la necesidad cultural de un alimento que se considera vital a lo largo de toda la Edad Media y que Isidoro de Sevilla llegó a definir como aquello que acompaña necesariamente todo tipo de alimento, hasta el punto de constituir, junto con el vino, uno de los dos elementos imprescindibles de que consta la más simple de las comidas (Etimologías, $\mathrm{XX}$, ii. 5 y 15).

Cabría preguntarse, pues, qué evidencia material puede dejar una actividad doméstica tan importante como es la elaboración y cocción del pan en el registro arqueológico medieval. Esta requiere determinados pasos previos ligados a la transformación del cereal como son la siega, trilla, almacenaje del grano y molienda en molinos mecánicos o manuales. Dichos aspectos de la producción, que pueden dejar importantes evidencias arqueológicas, exceden por su especificidad el marco propuesto para este estudio. Nos interesan aquí las evidencias materiales ligadas al proceso de panificación propiamente dicho, es decir, el amasado de la harina con agua y levadura en artesas o recipientes cerámicos semejantes a los lebrillos o alcadafes (Fig. 1), la fer- 

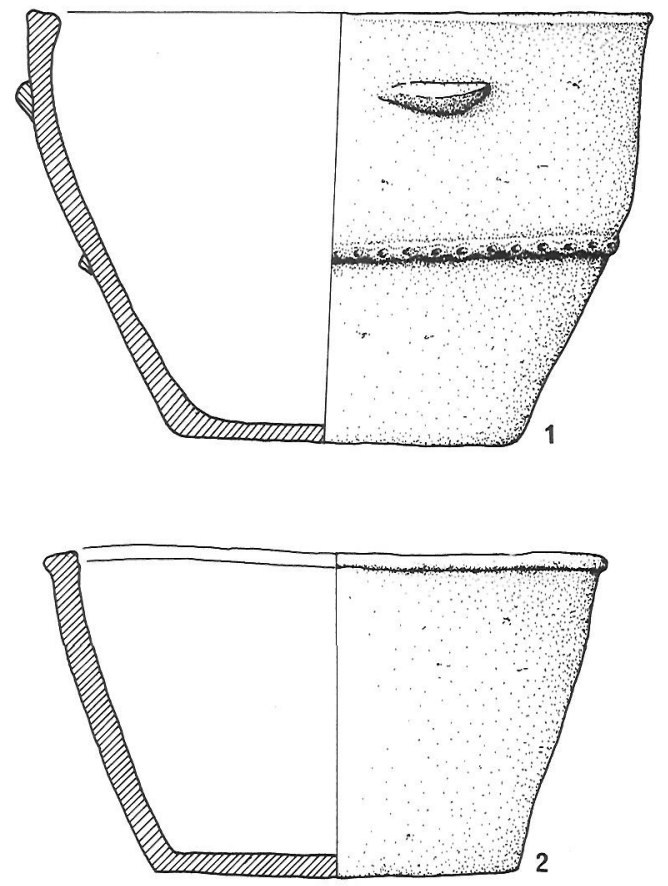

Fig. 1.-Alcadafes. Zambo (Novelda, Colección M. Romero).

mentación de la pasta y fundamentalmente la cocción, siendo el objeto de este trabajo por su obvia dimensión arqueológica, los diversos aparatos de cocción que constituyen un útil cerámico. Para ello debemos recurrir nuevamente a un texto de Ibn al-c'Awwām, según traducción de Banqueri, (1988; Facs. 1802, Vol. II 358-59):

«El modo de cocer el pan es poner la masa bien blanda en caldero nuevo, y meter este en el horno después de bien y no fuertemente caldeado, donde dexándole hasta cocerse aquella, sale el pan de mas sazonada cochura que el del horno común (furn), mas liviano que el subcinericio (mallā), mas tiempo que el cocido en hornillo (tannūr) y sarten (țābaq), y más digestible y de más alimento (sic).»

El texto menciona al menos cuatro formas diversas de cocer el pan: el horno, el hornillo, la sartén y la cocción directa en el rescoldo. El llamado «horno común» debe referirse, de acuerdo con la opinión de G. Rosselló (1990), al horno propiamente dicho, es decir, al horno de obra no transportable, que genera una estructura constructiva, objeto más bien de un trabajo sobre arquitectura doméstica que de un estudio sobre objetos cerámicos como el que nos ocupa. Este tipo de horno parece haber sido difundido en el Próximo Oriente y quizá también en el norte de Africa por los romanos (FORBES, 1966, 65); de la misma forma que la propia palabra que lo designa en árabe ((furn)) parece ser también un préstamo lingüístico del latín (CINTAS, 1962, n. 24).

El pan subcinericio — subcinericius o focacius de San Isidoro (Etimologías, XX, ii, 15)- es decir, la hogaza cocida directamente en el rescoldo o debajo de la ceniza del hogar, nos remite a un sistema de cocción que no se relaciona con ningún objeto cerámico específico. Se trata de una torta con levadura (pasta agria del día anterior) o sin ella, que se vierte sobre las brasas y cenizas de un hogar (que a su vez puede ser el rescoldo de una simple hoguera o una estructura construida con barro, guijarros, etc.), cubriéndose por las mismas a fin de efectuar la cocción. Una forma de cocción similar a ésta es la que realizan las comunidades tuaregs del Ahaggar en el Sahara Central, con la particularidad de que la torta es cocida en arena caliente y recubierta con la misma. Una vez efectuada la cocción, que dura unos treinta minutos, se limpia y lava con agua, tomándose en trozos con mantequilla fundida, leche o una salsa (S. V. A164 «Alimentation», ENCYCLOPÉDIE BERBĖRE, 1987. Gast. 525).

Por el contrario, las dos formas restantes de cocer el pan mencionadas por el tratadista medieval, el hornillo y la sartén, sí pueden convertirse en una evidencia arqueológica directa como útiles cerámicos que son. Su uso ha desarrollado formas funcionales que comienzan a reconocerse en los yacimientos peninsulares y que cuentan con significativos paralelos a ambos lados del Mediterráneo.

\section{EL FOGÓN PORTÁTIL U HORNILLO DE ATANOR (Tannūr)}

El punto de partida para la individualización de este objeto está ligado a las primeras campañas de excavación sistemática del yacimiento alicantino de la Rábita de Guardamar del Segura (AZUAR, $1985,1986,1987$ y 1989). La aparición de numerosos fragmentos cerámicos difícilmente interpretables, caracterizados por presentar haces de líneas incisas en el interior - con un valor obviamente ale- 

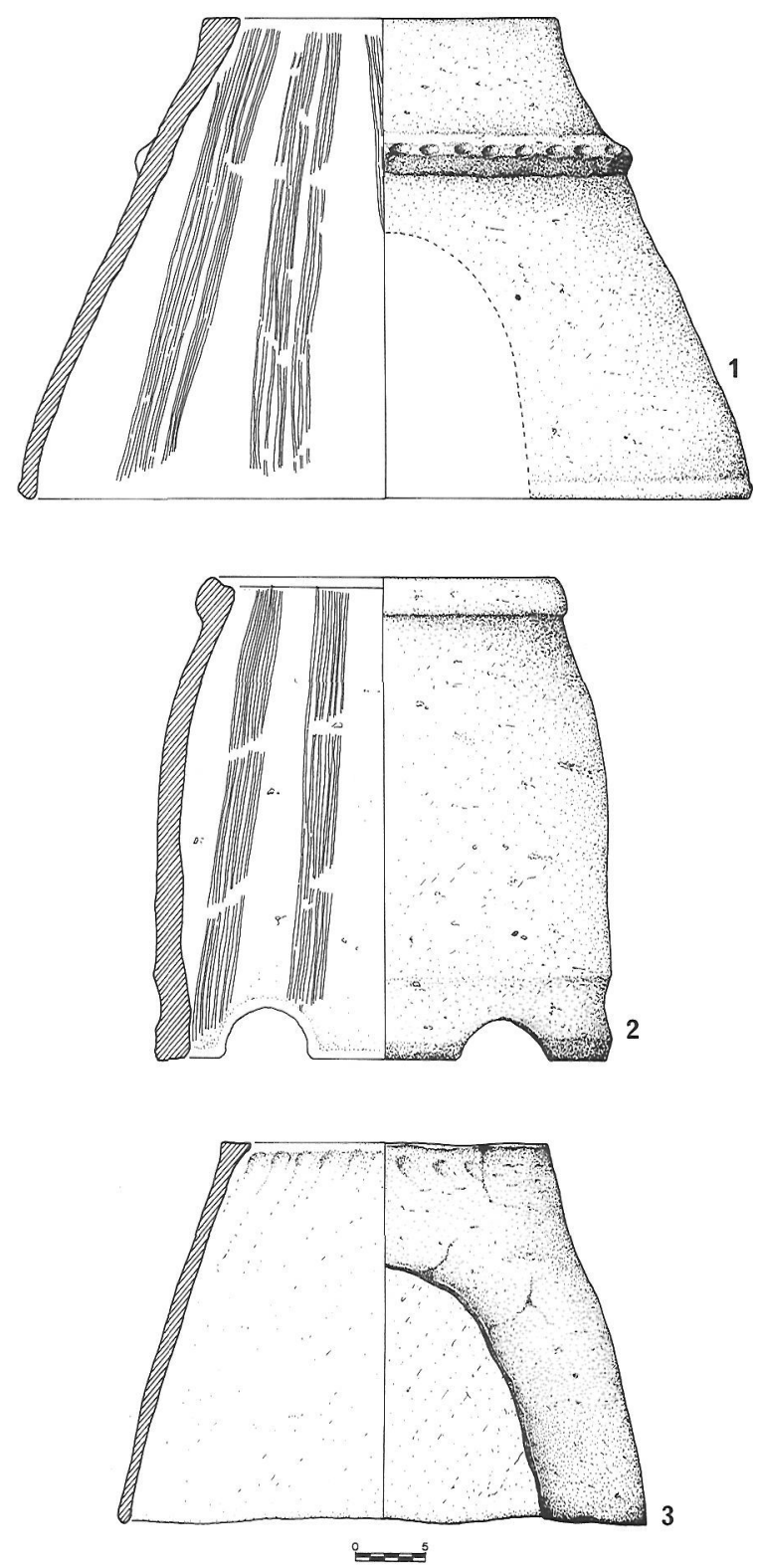

Fig. 2.-Fogones u hornillos portátiles. 1 y 2: Rábita de Guardamar (Alicante); 3: Sompo (Cocentaina).

jado del ámbito de lo decorativo- $y$, a menudo, con trazas de contacto con el fuego, permitió la laboriosa restitución de los perfiles de dos piezas, hasta entonces desconocidas — con excepción, quizá, del anafe cilíndrico de Santa Catalina de Sena, publicado por Rosselló $(1978,76-7)$ - y que interpretamos como anafes u hornillos portátiles (GUTIERREZ, 1987 y 1988). Se trataba de piezas cilíndricas (tipo A) o cónicas (tipo B), abiertas por ambos

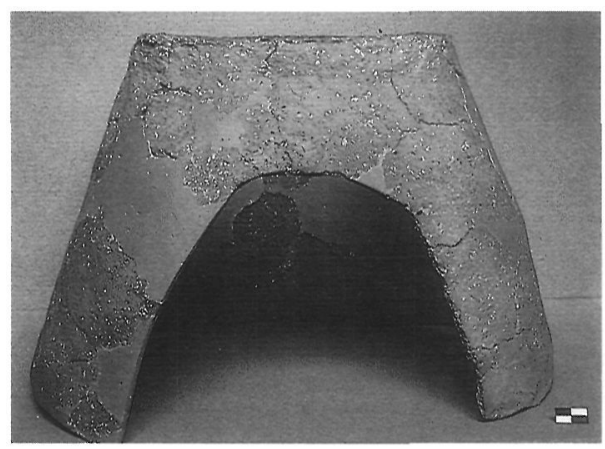

Lám. 1.- Fogón del «Sompo» (Cocentaina).

lados, modeladas a mano con decoración de cordón digitado en un caso (B) y evidencia de pequeñas ventanas semicirculares en la base del otro (A) (Fig. 2). La reconstrucción de estos fogones, inicialmente intuitiva, se reveló acertada - al menos para el tipo troncocónico, con la salvedad de la gran boca oval que debería de tener- al aparecer nuevos paralelos completos procedentes del «Sompo» en Cocentaina (Alicante) y de Madrid (TURINA y RETUERCE, 1987, 177) (Lám. 1). Las dimensiones de la única pieza entera, el ejemplar del Sompo, son $23,3 \mathrm{~cm}$. de diámetro superior, $37,5 \mathrm{~cm}$. de diámetro inferior y $25 \mathrm{~cm}$. de altura; los ejemplares de Guardamar tienen un diámetro superior de unos $25 \mathrm{~cm}$. y una altura hipotética de unos $35 \mathrm{~cm}$., mientras que el diámetro inferior varía de unos $32 \mathrm{~cm}$. para el tipo A a unos $50 \mathrm{~cm}$. para el $\mathrm{B}$.

Una vez definidos los perfiles, han comenzado a reconocerse fragmentos de estas piezas en yacimientos de cronolgía emiral y califal como son, además de Guardamar, los asentamientos alicantinos del«Zambo» en Novelda, el Castillo de Callosa de Segura, el «Cabezo Soler» en Rojales, la«Llometa del Sifó» en la rambla del Vinalopó y próximo a Elche; los asentamientos albacetenses del «Tolmo de Minateda» en Hellín y el«Castellar de Sierra» en Tobarra o el murciano del«Castillejo de Barinas» en Abanilla (Fig. 3). Se trata, pues, de útiles que empiezan a ser significativos en los contextos altomedievales rurales y cuya función, según se desprende de los datos arqueológicos y etnográficos que veremos a continuación, parece relacionarse con el proceso de fabricación del pan.

Las piezas en cuestión son hornillos o fogones portátiles - de hecho, el grueso de las piezas de la Rábita de Guardamar procede de las calles - aptos para múltiples usos vinculados con la calefacción y 

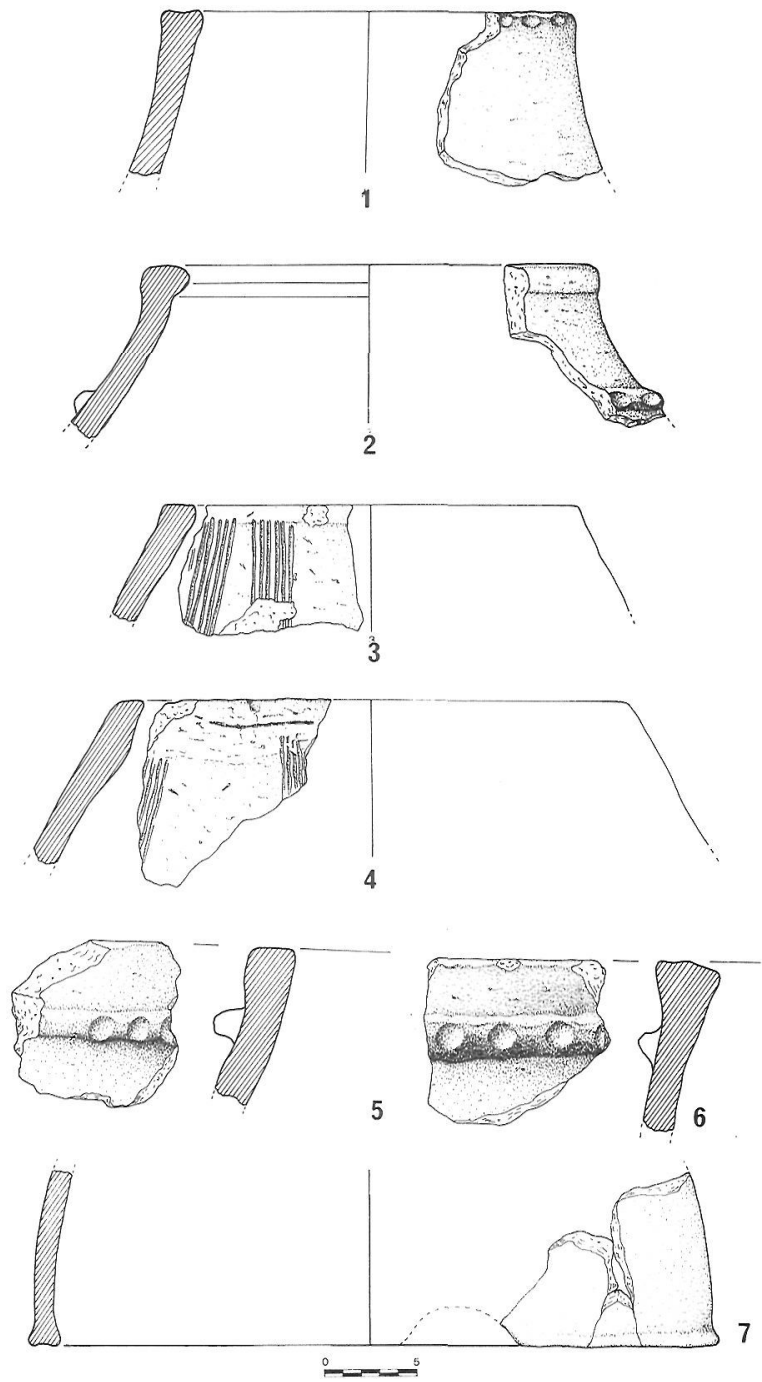

Fig. 3.-Fogones u hornillos portátiles. 1: Castillejo de Barinas (Abanilla); 2: Zambo (Novelda); 3: Castillo de Callosa (Callosa del Segura); 4: Castellar de Sierra (Tobarra); 5 y 7: Rábita de Guardamar (Alicante); 6: Tolmo de Minateda (Hellín).

la cocina, pero especialmente destinados a la cocción de un tipo de pan, generalmente ázimo. La levadura, en caso de utilizarse, puede ser el fermento tradicional a base de harina de mijo mezclada con mosto y dejada secar (citado por Ibn al-cAwwām) o lo que parece más verosímil, en opinión de L. Bolens $(1980,467)$, un poco de pasta fermentada del día anterior, con lo que el producto resultante es un pan, mejor torta o alcorza, redondo y poco hinchado. Los fogones están modelados en arcilla mezclada con abundante y grueso desengrasante mineral (in-

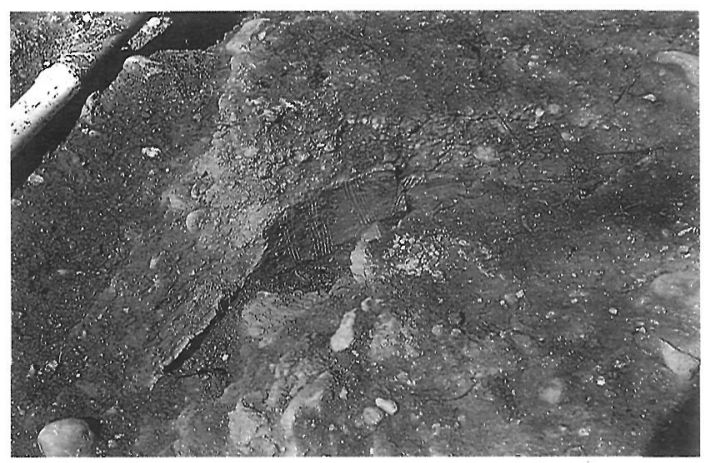

Lám. 2.- Hogar del Castillo del Río (Aspe), (fotografía: Rafael Azuar).

cluyendo en ocasiones fragmentos de cerámica), vegetal (fundamentalmente paja) o incluso estiércol, como parece ser frecuente en hogares de otras áreas geográficas (COUSIN, 1989) y, a menudo, pueden estar únicamente cocidos de forma parcial, por la reiterada exposición a las llamas. Es frecuente, aunque no estrictamente necesaria, la existencia de haces de líneas incisas - paralelas en los ejemplares más antiguos o entrecruzadas en los más modernos - cuya presencia parece estar vinculada a su carácter de recipientes de fuego, bien para evitar el resquebrajamiento de las paredes bien para facilitar la adherencia del pan. En cualquier caso, esta característica se constata también en las paredes internas del hogar troncocilíndrico de barro, parcialmente cocido, aparecido en el «Castillo del Río» en Aspe, Alicante, con unas dimensiones de veinticinco centímetros de diámetro por quince de altura máxima conservada (AZUAR, 1988) (Lám. 2).

El funcionamiento de estos hornos, bien descrito por un autor del siglo XIII, Ibn Razin alTuyibi, y más recientemente por P. Cintas (1962, 234) y R.J. Forbes (1966, 63-4), es perfectamente reconstruible; además, aun hoy se siguen utilizando en Oriente y en el Maghreb (Fig. 4). El hornillo, tanto cilíndrico como troncocónico, se apoya sobre el suelo o, incluso, puede estar total o parcialmente enterrado en él, como parece ser frecuente en $\mathrm{Pa}$ lestina. Debe contar con al menos dos aberturas: la superior - ojo - para la evacuación de humos y la inferior - boca- (tanto una sola de gran tamaño como varias más pequeñas) que actúa como tiro y sirve para cargar y limpiar el horno de combustible. Este puede ser madera (ramas y arbustos), paja, estiércol o también orujo. Con todos los orificios abiertos se enciende un fuerte fuego en el inte- 


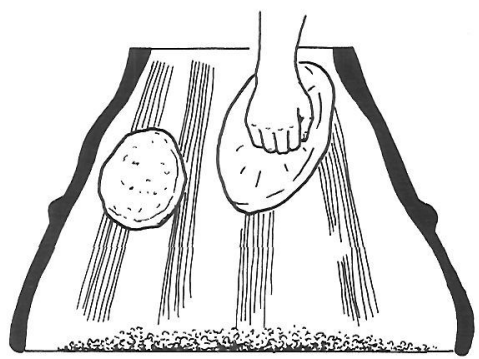

Fig. 4.-Reconstrucción del funcionamiento de un tannūr.

rior, que sale como una antorcha y calienta intensamente las paredes (en algunos casos, el horno puede calentarse desde el exterior cubriéndolo con el combustible). Cuando el fuego se ha reducido a brasas, se introducen los panes o alcorzas por la abertura superior con ayuda de una especie de cojín de cuero o simplemente con la mano mojada según Ibn Razin al-Tuyibi y se adhieren a las paredes, donde se cuecen cerrando todas las aberturas con tapaderas de barro - cabría plantearse como hipótesis si alguna de las abundantes tapaderas planas con señales de fuego en el interior aparecidas en contextos altomedievales no podría relacionarse con esta función (GUTIERREZ, 1988, 59-60 y 88) (Fig. 5) - piedras o incluso, en el caso del tiro su-

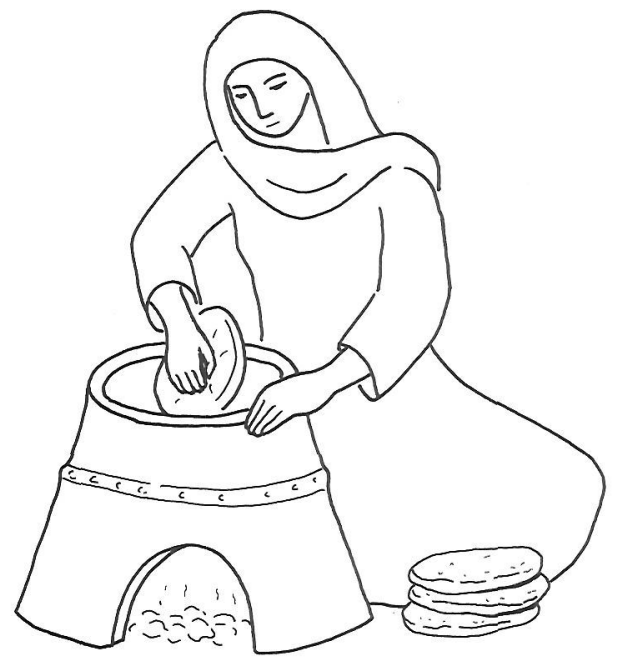

perior, con una marmita. Según se quiera avivar más o menos el fuego se abren las aberturas y se atizan las brasas removiéndolas. Cuando el pan está cocido se extrae de la misma forma y se vacían las cenizas por la abertura inferior.

Este tipo de fogón es la forma más común de horno de cocción en el Próximo Oriente y responde a una tradición conocida en toda la antigüedad semítica, hasta el punto de que el nombre con el que se conoce hoy en Palestina - tannūr - parece relacionarse con la raíz acadia tinuru (CINTAS, 1962, 235). El tannūr es el horno de pan, troncocónico o cilíndrico con boca y ojo, de gran tamaño —unos 70 ó $100 \mathrm{~cm}$. de altura por 50 ó 60 de diámetro (FORBES, 1966, 64) - y construido sobre el suelo
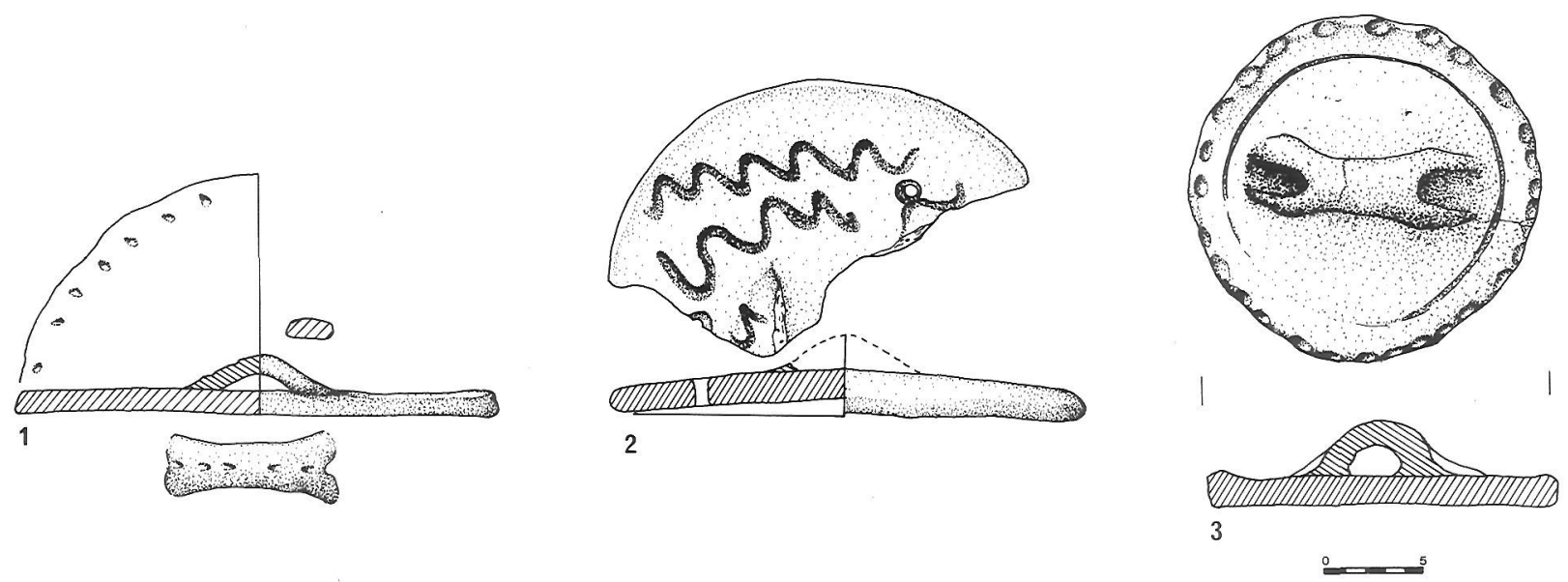

Fig. 5.-Tapaderas planas 1 y 2: Alcudia (Elche); 3: Zambo (Novelda). 


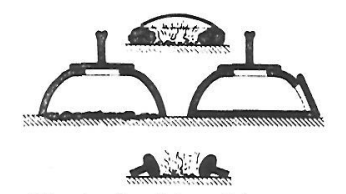

The sîh, the tratbun and the zantiu.
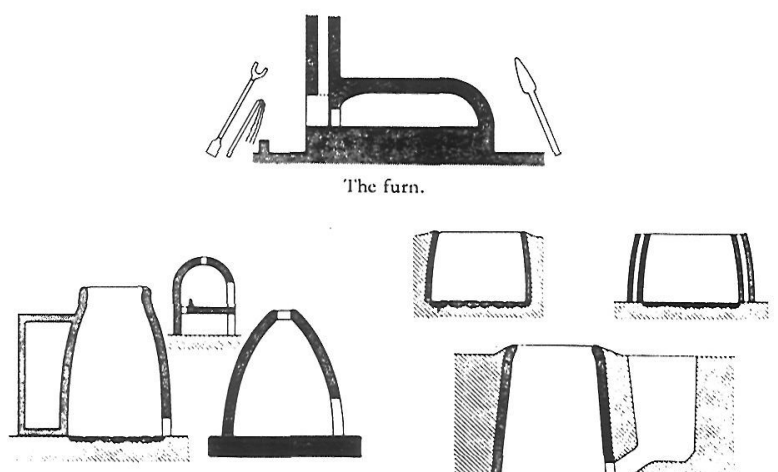

The 'arsa and five types of the tannutr.

Fig. 6.-Diversos tipos de țābūn y tannūr (según FORBES, 1966, Fig. 9).

o enterrado en él. De otro lado, țābūn o țābūna, ambos de la raíz «TBN» = «guardar el rescoldo», es el nombre que recibe, fundamentalmente en el norte de Africa, una estructura similar aunque de menor tamaño $-26 \mathrm{~cm}$. de diámetro superior y 26 $\mathrm{cm}$. de altura (FORBES, 1966, 64) - y claramente portátil, muy similar a nuestros ejemplares (Fig. 6). El uso de este tipo de horno está atestiguado desde muy antiguo en el norte de Africa como lo demuestra el hallazgo, a principios de los años sesenta, de una terracota en la necrópolis púnica de Bordj Jedid en Cartago (CINTAS, 1962; TLATLI, 1978, 123, Fig. 24), en la que se muestra a una mujer cociendo panes en un horno de similares características a los actuales tanānīr o tẩbunat, y por la pieza reconstruida - conocida como el «țābūn Saumagne»- procedente de los niveles púnicos del barrio de Métroon, también en Cartago, de forma troncocónica con tres aberturas semicirculares en su extremo inferior (LANCEL, 1979, 303-4) y cuyo parecido con nuestro fogón del tipo A no deja de ser sorprendente (Lám. 3). Sin embargo, si bien el țābun u hornillo portátil era utilizado tradicionalmente desde la protohistoria, su extensión generalizada por el Próximo Oriente (FORBES, 1966, 64) y por el Maghreb (CINTAS, 1962, 239) parece vincularse a la conquista árabe. Este horno se sigue utilizando hoy en numerosos lugares del norte de Africa, especialmente en Túnez —donde Cintas fotografió

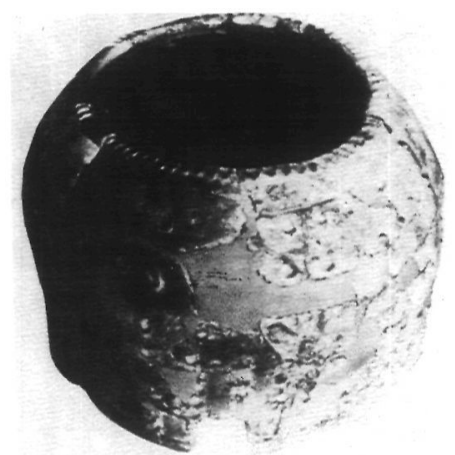

Lám. 3.- Tăbun Saumagne (fotografía: Cintas, 1962, Tav. LVI-3).

uno procedente de Nabeul (Fig. 7)-y en Argelia, donde en algunos oasis como Tabelbala, Mlouka o Koussan «...a perduré la tradition du four de poterie cylindrique, parent direct du tannur du Proche Orient et de la tabuna tunisienne mais de dimensions réduites. Sur ses parois chauffées à blanc, on plaquait quelques pains circulaires, parfois fourrés d'oignons hachés, de pimients et de petits morceaux de graise». (S.V. A164 «Alimentation». ENCYCLOPÉDIE BERBËRE, 1987, Champault, 513).

Aunque su uso más generalizado es el de horno de pan; su carácter de contenedor de fuego portátil les puede proporcionar otros usos (1) no estrictamente culinarios. En Palestina, hornos de estas características se podían utilizar para cocer barro o para fundir metal (FORBES, 1966). La excavación

(1) Pueden utilizarse para asar y cocer toda clase de alimentos o transformar otros, como ocurre en Rajasthan (COUSIN, 1989), donde, poniendo a hervir la leche lentamente en el interior de un hornillo cilíndrico, se obtiene mantequilla.

Como un posible uso subsidiario de estos cilindros cerámicos cabe señalar la interesante sugerencia de Paul Arthur, cuya amabilidad agradezco desde aquí, relativa a su utilización como colmenas. Esta posible función - para la cual, sin embargo, no creemos que fueron concebidos- podría relacionarse con el hallazgo de numerosos fragmentos de fogones del tipo A en la partida ilicitana de la «Llometa del Sifó», recogidos por el Grupo Ilicitano de Estudios Arqueológicos y depositados en el Museo Arqueológico Municipal de Elche (algunos fragmentos de antiguos hallazgos en IBARRA, 1926, pp. 110, caja 114 y pp. 114). Las características del hallazgo -son prácticamente las únicas formas recogidas y bastante numerosas, la inexistencia de señales de uso como recipientes de fuego y la ausencia en las cercanías de evidencia de hábitat- llevó incluso a sus descubridores a plantearse tal posibilidad. Agradezco a P. Ripoll la noticia del hallazgo y de sus condiciones. 

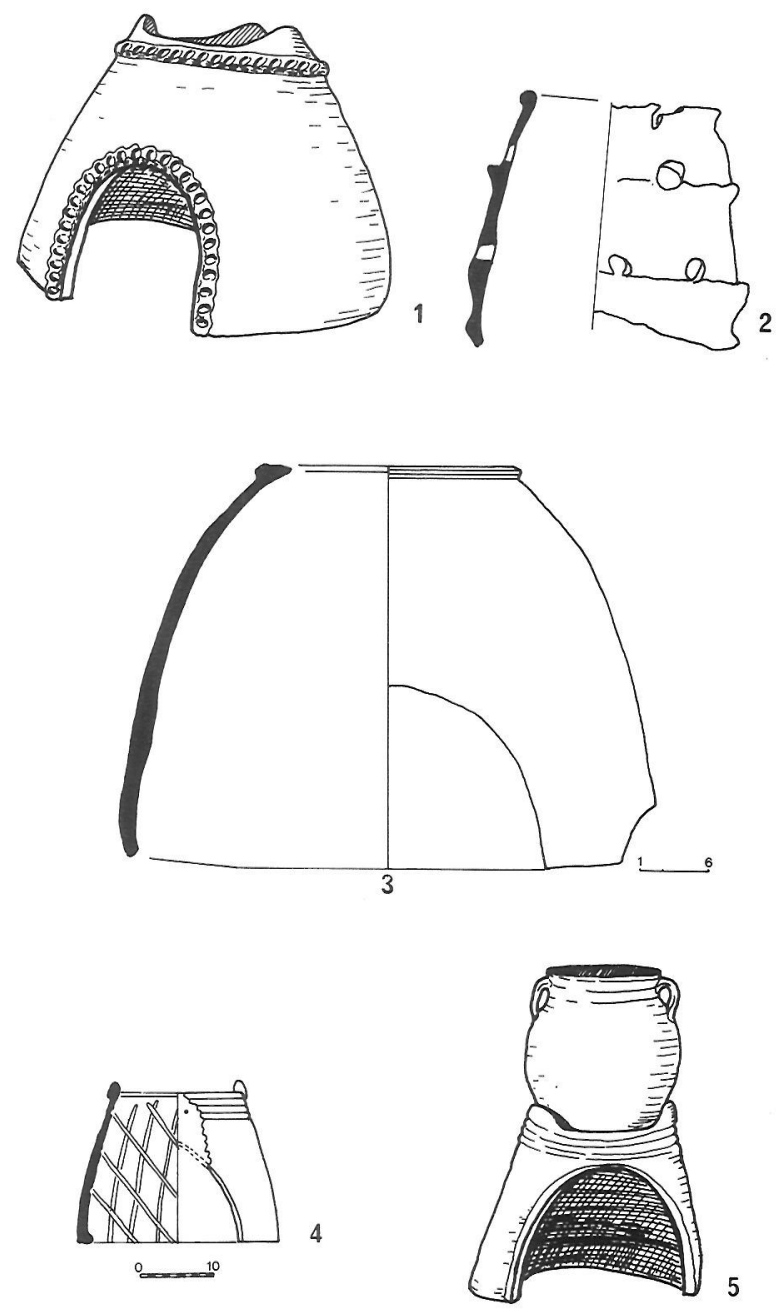

Fig. 7.-1: țābūn de Nabeul (según fotografía de CINTAS, 1962, Tav. LVI-2; 2: anafe de Santa Catalina de Sena (según ROSSELLO, 1978, Fig. 19-B); 3: fogón del «Palau Real» de Valencia (según COLL et alii, 1988, n. ${ }^{\circ}$ 53); 4 y 5: fogón de Paterna (según MESQUIDA y AMIGUES, 1986, Lám. 1 y SOLER, 1988, 174).

en Byrsa de unos talleres metalúrgicos, donde se hallaron dos fosas semiesféricas de más de $60 \mathrm{~cm}$. de diámetro rellenas de ceniza y rodeadas de un anillo rojizo de tierra cocida, escoria de metal y numerosos fragmentos de cerámica con impresiones, permitió identificar dichas estructuras como posibles fondos de hornos tipo «bowl-furnace». Dichos hornos deberían tener una superestructura cónica o cilíndrica móvil a la que corresponderían los fragmentos cerámicos hallados en la excavación. La hipotética superestructura cerámica podría relacionarse formalmente con las «țâbūnat»u hornos de pan y en concreto con el famoso «tāabūn Saumagne», al que nos hemos referido con anterioridad, hallado también en Byrsa en 1925 y que, en opinión de Thullier (en LANCEL, 1982, 250-55), podría reinterpretarse como parte de un horno de metal. En este caso, las aberturas semicirculares actuarían como toberas, permitiendo con un fuelle avivar el fuego, según la reconstrucción propuesta por Thullier (Fig. 8), a pesar de no haberse hallado restos de las mismas en la excavación. Quizá, el hogar del Castillo del Río, en Aspe, podría relacionarse con estructuras de este tipo destinadas a la forja.

A diferencia de otros útiles cerámicos relacionados con la cocción del pan, estos fogones portátiles no aparecen, hasta el momento que sepamos, en contextos tardorromanos, por lo que parece obvio que a pesar del antiguo origen de estas piezas en otros puntos del Mediterráneo y del Próximo Oriente, en la Península sólo comienzan a ser significativas en yacimientos de cronología emiral y califal, siendo posible vincular su aparición a la entrada de la Península en la órbita cultural islámica y a la llegada de poblaciones del Maghreb y respondiendo, en opinión de L. Bolens $(1980,467)$ a un nivel de «cultura antigua», propio de asentamientos de temprana cronología o de carácter rural, ya que el tannūr sería paulatinamente desbancado en los contextos urbanos por el horno de obra (furn), con mayor capacidad y un mejor mantenimiento del calor. Sin embargo, si bien estos útiles no aparecen en contextos preislámicos, sí perviven como forma en uso a lo largo de toda la Edad Media perdurando incluso en época bajomedieval cristiana. Fragmentos de fogones con incisiones internas entrecruzadas y cordones en relieve aparecen en los yacimientos alicantinos de Pusa en Petrel, fechables en el siglo XII (NAVARRO, 1988, 21-2); en el Castillo de Cocentaina y en el silo de la Plaza de Sant Miquel, también en Cocentaina, con cronologías en este último caso de fines del siglo XII y principios del XIII (AZUAR, 1989, 112-117) o en el Castillo de Río en Aspe con idéntica cronología (2). Ya de contextos cristianos son dos significativas piezas procedentes de tierras valencianas; una proviene del «Palau Real» de Valencia y se fecha entre la segunda mitad del siglo XIII e inicios del XIV (COLL,

(2) Según comunicación de Rosa Saranova que ultima un estudio sobre el mobiliario cerámico de ámbito doméstico relacionado con el fuego en dicho yacimiento. 

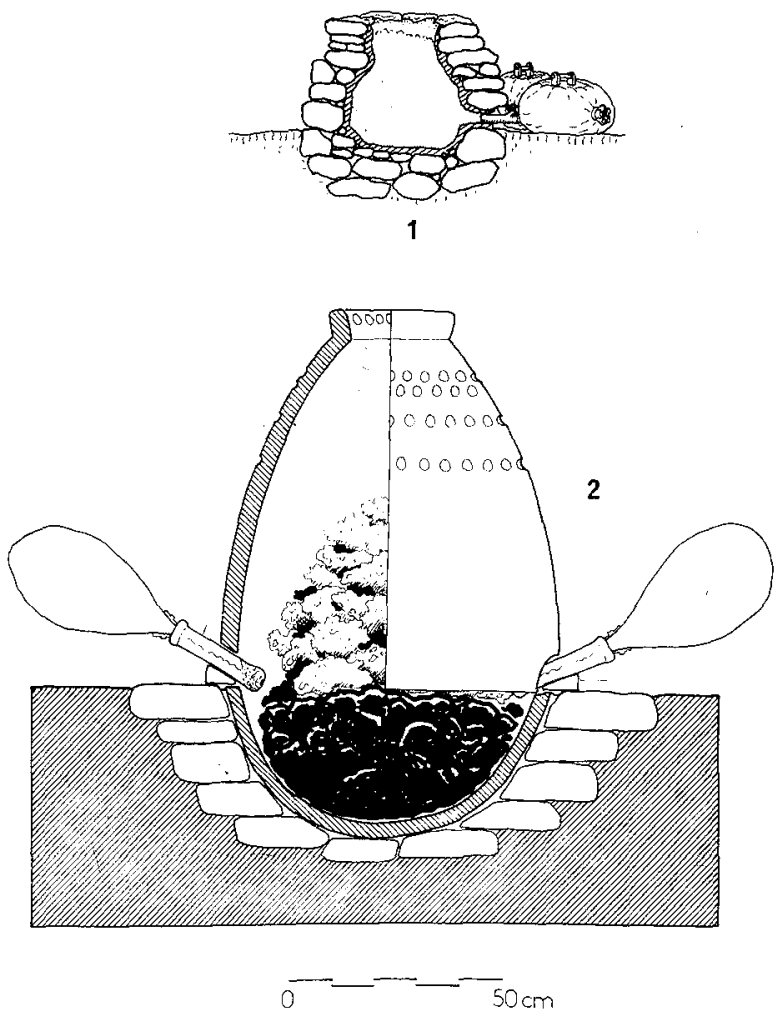

Fig. 8.-Hornos de metal. 1: fundiciones indias (según SHERBY y WADSWORT, 1985, Fig. 2): 2: reconstrucción de los hornos metálicos de Byrsa según THULLIER (apud LANCEL, 1982, Fig. 327).

MARTI, PASCUAL, 1988, 88, n. 53), formalmente es similar a nuestro tipo $B$ y también presenta incisiones internas entrecruzadas. La otra pieza, de menor tamaño, procede de Paterna y presenta junto a las características incisiones tres protuberancias para apoyar una olla (MESQUIDA y AMIGUES, 1986, 542 y Lám. 1; SOLER, 1988, 174). Se trata en este caso de un anafe o fogón para cocinar con ollas, más que de un horno de cocción de pan propiamente dicho. (Fig. 7).

En cualquier caso, no sólo está perfectamente atestiguada la pervivencia de la forma, sino también la del nombre. En el manuscrito de Ibn al-'Awwām se utiliza la palabra tannūr para referir el hornillo portátil a diferencia de furn para la obra estable. Según Guillermo Rosselló, que realiza un exhaustivo estudio sobre terminología cerámica, los términos tạ $b \bar{u} n$ o tă $\bar{b} \bar{u} n a$ no fueron vocablos andalusies - a pesar de su generalizado uso actual en el norte de Africa- mientras que el término tannūr sí lo fue, estando además en uso desde el siglo XI (3). Este último término ha dado en castellano la palabra «atanor», que en el sentido de «hornillo de atanor» se refiere, según el Diccionario de la Real Academia, «al aparato usado por los alquimistas y en el cual el carbón que servía como combustible se cargaba en un tubo o cilindro central, desde donde bajaba al hogar para ir alimentando el fuego. Varias aberturas dispuestas alrededor permitían hacer diversas operaciones al tiempo». Los otros sentidos actuales de la palabra - cañería para conducir el agua o cada uno de los tubos de barro cocido de que suele formarse dicha cañería- parecen inspirarse en el carácter de cilindro cerámico que tiene el objeto definido en todos los casos. Dicho aparato, denominado con una palabra de origen árabe, y cuyo uso ha quedado relegado al campo de la alquimia, no es más que un fogón portátil sobre el que se colocaban el matraz y los alambiques - piezas estas últimas documentadas arqueológicamente en Al-Andalus (BOSCH y CHINCHILLA, 1987, 496) - para destilar diversas sustancias. Algunas miniaturas, como la procedente de un manuscrito británico del siglo XV (Fig. 9), ilustran modelos de hornillos de atanor muy semejantes a las piezas medievales que estudiamos.

Si consideramos nuestros tanānūr o atanores como hornos portátiles, generalmente de pan, característicos de contextos rurales en algunas áreas de Al-Andalus, hemos de preguntarnos si existen formas similares de época medieval en zonas exteriores al ámbito cultural islámico. Un conjunto de piezas cerámicas italianas, agrupadas bajo la denominación genérica de «catini-coperchio da fuoco» reflejan, en nuestra opinión, idénticas necesidades funcionales con soluciones formales distintas. Se trata de una especie de tapaderas en forma de campana cerámica con una o dos asas o bien un reborde a media altura, que debian funcionar como «fornetti portatili, riproducendo in versione ridotta le stesse condizioni dei forni da panificazione» (BROGIOLO y GELICHI, 1986, 312). La difusión de estas piezas es relativamente amplia en la Península Itálica, ya que aparecen tanto en el norte como del

(3) Aprovecho estas líneas para agradecer a Guillermo Rosselló Bordoy las valiosas referencias y acertadas matizaciones sobre la adecuada denominación de esta forma cerámica y la información que amablemente me proporcionó sobre los datos contenidos en la obra de Ibn Razin al-Tuyibi. 

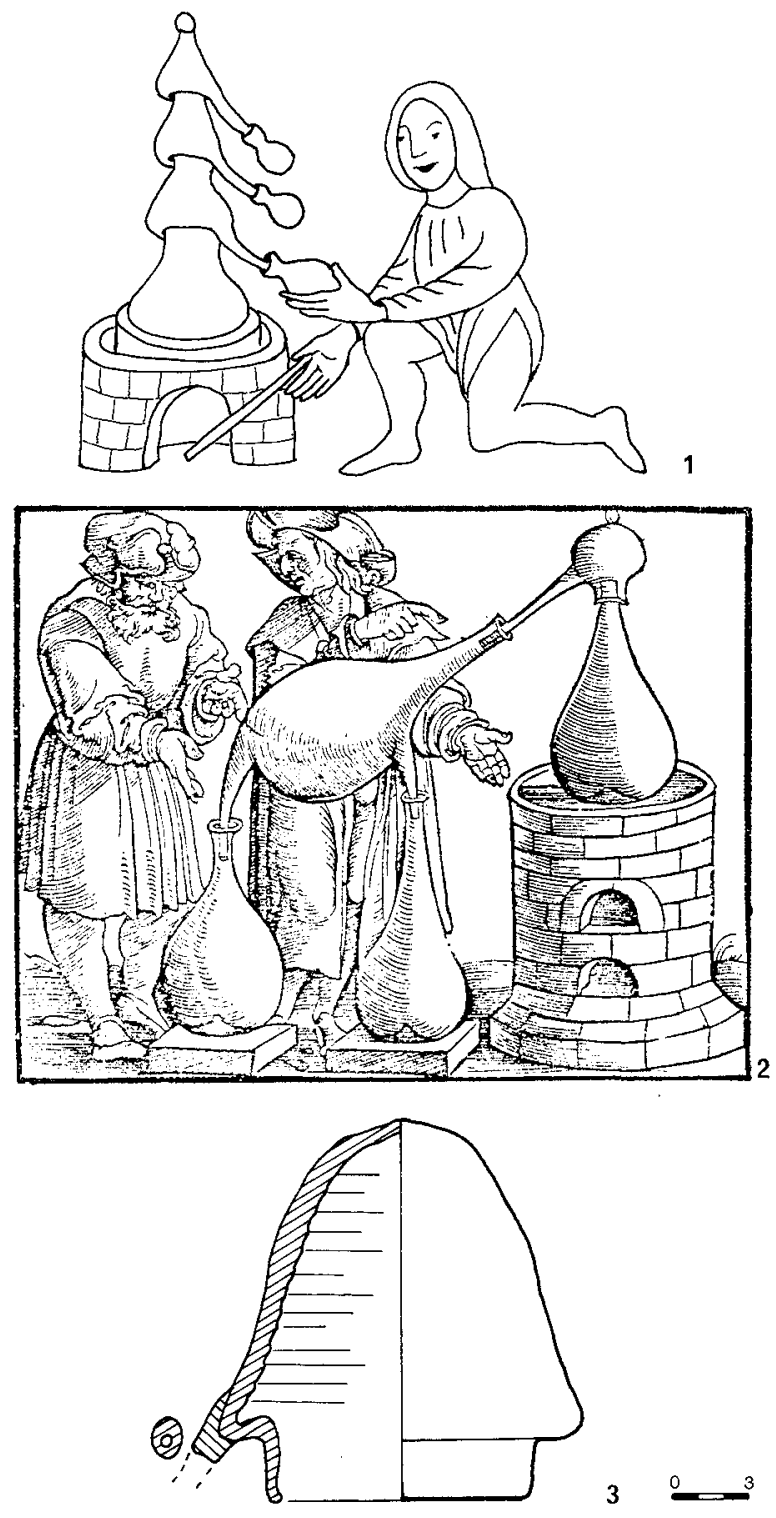

Fig. 9.-1: alquimista con atanor, matraz y alambiques según manuscrito inglés del siglo XV (Museo Británico); 2: grabado del Gran Libro de la Destilación de Jerónimo de Brunswick (Estrasburgo, 1519); 3: alambique de Córdoba (según BOSCH y CHINCHILLA, 1987, Fig. 2-7).

centro-sur: Classe en Ravena, Ferrara, Piadena y Brescia (BROGIOLO y GELICHI, 1986), Monte Barro en Como (NOBILE, 1988, 202-3), la Crypta Balbi en Roma (MANACORDA et alii, 1986, 537, Tav. XII), en Atri (STAFFA, 1986, 445-6, Fig. 2), o en el Valle del Volturno (HODGES y PATTERSON, 1986, Fig. 5-20). La cronología de estas formas es amplia, extendiéndose desde contextos alto- medievales con dataciones de los siglos VI y VII en Monte Barro o Classe, hasta contextos bajomedievales, como los de Brescia, fechados en los siglos XIII y XIV, para desaparecer, por fin, en la segunda mitad del siglo XV (Fig. 10).

Su origen ha sido objeto de una reciente e interesante discusión. Joan Frayn relaciona estas tapaderas de cocción con el método de panificación $s u b$ testu, citado por distintos autores clásicos y propio, según esta autora, de ámbitos domésticos rurales. Frente a este sistema ristico y familiar, los hornillos portátiles - como el clibanus o el thermospodium - eran más propios de casas acomodadas, tanto en ambientes rurales como urbanos, y el horno propiamente dicho - furnus - era el sistema de cocción estándar relacionado con la panadería indus-
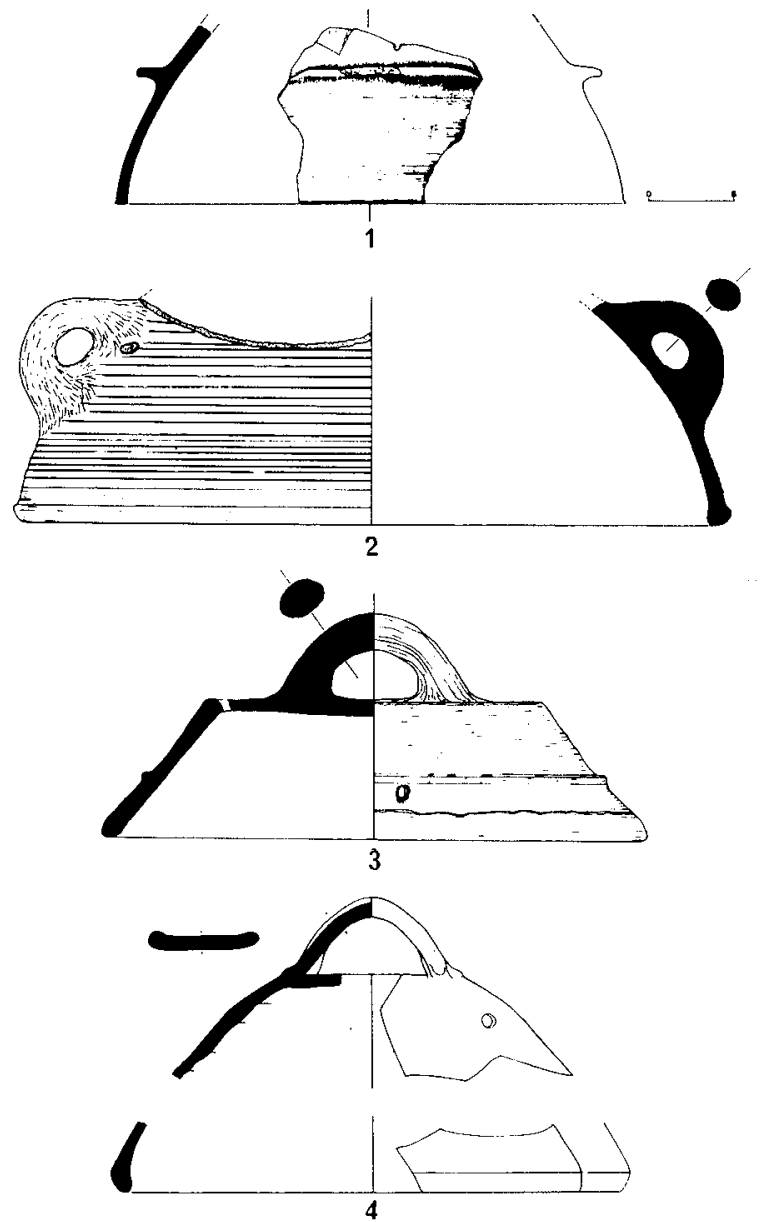

Fig. 10.- Hornos portátiles de pan italianos. 1-3: Classe, Piadena y Brescia (según BORGIOLO y GELICHI, 1986, Tav. III-5, V-3, VII-4); 4: Cryta Balbi, Roma (según MANACORDA et alii, 1986, Tav. XII-8 y 9). 
trial, apto para alimentar a las clases pobres urbanas y a los trabajadores de los grandes dominios rurales (FRAYN, 1978). Su funcionamiento es muy sencillo: sobre un montón de carbón encendido se coloca la campana hasta que se calienta, a continuación se levanta y se aparta rápidamente el carbón para colocar la masa sobre el suelo caliente y cubrirla con la tapadera, amontonando el carbón sobre ésta para mantener la temperatura y permitir que el pan se cueza. Muy recientemente han sido matizadas algunas de estas consideraciones por parte de tres autores - Cubberley, Lloyd y Roberts (1988)que consideran que los términos testum y clibanus son, en realidad, intercambiables y se refieren en época clásica a una misma forma - la tapadera de cocción-, cuyo uso se documenta arqueológicamente desde el siglo II a.C., no sólo en los ámbitos rurales sino también en los ambientes urbanos. A partir del siglo III se aprecia un constante descenso en el uso de estas piezas, que los autores relacionan, quizá, con la llegada de recipientes de cocción importados de Africa como la forma de ARS Hayer 23. A partir de época tardorromana y es de suponer que en relación con el fin de las importaciones de cerámicas finas y el desarrollo de las producciones locales, estos clibani vuelven a ser significativos en los repertorios arqueológicos, aunque con cambios en el tamaño y en los perfiles, fruto quizá de las transformaciones en la dieta alimenticia (CUBBERLEY, LLOYD y ROBERTS, 1988, 110 y ss.). Se trata, por tanto, de piezas cuyo origen se remonta a la época protohistórica y cuya tradición se mantiene durante la época romana en ámbitos rurales y urbanos, republicanos y altoimperiales, comenzando a declinar a partir del siglo III para reaparecer con fuerza a fines de la antigüedad tardía, hasta el punto de constituir, junto con la olla, el elemento característico del altomedievo en algunas regiones de la Italia septentrional (BROGIOLO y GELICHI, 1986, 296 y 312).

La tradición de hornos de panificación portátiles, fabricados en arcilla cocida, ha pervivido en determinados ambientes rurales del interior de la Península Ibérica, hasta el punto de generar una industria específica de carácter doméstico, que todavía se mantiene viva. Es el caso de los hornos de Pereruela, Zamora, de gran tamaño y modelados a mano en forma de cúpula, con suelo y boca. La fabricación de estas piezas se relaciona con el resto de la actividad alfarera del pueblo, realizada exclusivamente por las mujeres en tornos bajos y especia- lizada en un reducido repertorio formal destinado al fuego y relativamente comercializado por la excelente calidad de sus barros para este menester (CORTES, 1954).

\section{EL PLATO DE PAN (țābaq)}

El texto de Ibn al-c'Awwām se refiere a otra modalidad de cocción portátil denominada tạa baq, término que Banqueri traduce por «sartén». Sin embargo, la palabra árabe țăbaq tiene el sentido de plato, fuente o tapadera, lo que en este contexto parece referirse a la bandeja de pan ázimo. El uso de grandes platos para hacer pan o similares está atestiguado desde época romana por las llamadas fuentes de «rojo pompeyano» (VEGAS, 1973, 47), a las que otros autores (CUBBERLEY, LLOYD y ROBERTS, 1988, 116) relacionan, junto con sus tapaderas, con otro tipo de aparato de cocción portátil: el thermospodium, considerado como un desarrollo en dos piezas a partir del testum. Quizá, a esta modalidad de cocción se refiera Isidoro de Sevilla al hablar del pan clibanicius, aquel «in testo coctus» (ETIMOLOGIAS, XX, ii, 15); es decir, aquel cocido en plato, disco o tapadera, piezas de las que existen evidencias arqueológicas en la época en la que escribe Isidoro de Sevilla. El funcionamiento de este utensilio es bien sencillo: en un lebrillo se amasa la harina con agua $y$, en ocasiones, un poco de pasta agria que actúa de fermento; se forman unas tortas redondas y planas que son cocidas en un plato de gran diámetro puesto sobre el fuego; generalmente es necesario dar la vuelta a la galleta para que cueza por ambas caras o bien cubrirla con el rescoldo. El resultado es un pan poco movido, mal cocido y de digestión pesada, que se trocea y consume con salsas, aceite o leche. Los recipientes suelen ser grandes platos, modelados a mano en pastas bastas con numerosas intrusiones y alturas variables que oscilan entre formas prácticamente planas verdaderos discos con un ligero reborde - y formas con altos bordes que recuerdan más a cazuelas que a platos. Esta modalidad de cocer el pan está muy extendida en la actualidad por todo el norte de Africa: en el alto Atlas marroquí, en el Riff, en el Aurès argelino o en Túnez (S.V. A164 "Alimentation». ENCYCLOPÉDIE BERBÈRE, 1987) (fig. 11).

Las bandejas de pan ázimo también están atestiguadas arqueológicamente en yacimientos anda- 


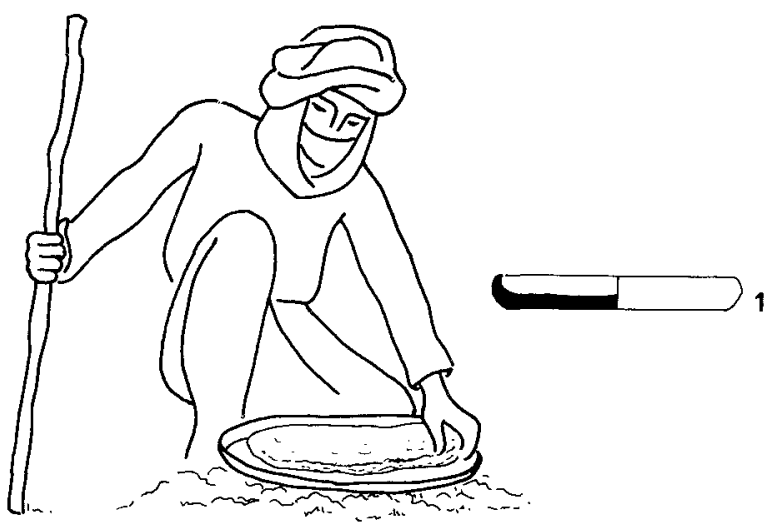

Fig. 11.- Cocción de la hogaza en el plato (tâabaq). 1: posible plato de pan (según PUERTAS, 1986-87, Fig. XVIII, F-1).

lusies como formas que perviven desde contextos emirales y califales, como son los de Pechina en Almería (ACIEN, 1986, IV, 262) (fig. 12) y Vascos en Toledo, (IZQUIERDO, 1979, 290, fig. 9-11 y 1983, 298, fig. 23), hasta contextos almohades como el de Castillejo de Los Guajares en Granada (ROSSELLO, 1990). Sin embargo, a diferencia del «tannūr» o atanor antes mencionado, la bandeja de pan o țā baq sí se constata en niveles tardorromanos, hasta el punto de constituir una de las piezas características de estos contextos. Este es el caso de la ciudad de Cartagena, donde en los niveles bizantinos, bien fechados por la Terra Sigillata Clara D tardía entre el último cuarto del siglo VI y el primero del VII, aparece con abundancia un tipo de cazuela o fuente para cocinar de gran tamaño -entre 30 y $40 \mathrm{~cm}$. de diámetro y 6 ó 7 de altura - de pastas muy bastas y con gran cantidad de variantes según sus bordes y sus bases (LAIZ y RUIZ, 1988). Creemos que estas «cazuelas» pueden interpretarse como bandejas de pan, aunque obviamente no fuera ésta su única función, ya que son aptas para ser utilizadas como tostadores de cualquier tipo de alimento. Además de los ejemplares de Cartagena, existe una pieza procedente de la necrópolis de Torreblanca del Sol, en Fuengirola, fechada en el siglo VI, que ha sido clasificada como base de horno. Sus características morfológicas - pasta muy basta y paredes muy gruesas - y sus dimensiones $-42 \mathrm{~cm}$. de diámetro por $6 \mathrm{~cm}$. de altura - la relacionan, en nuestra opinión, con las bandejas de Cartagena. Es de suponer que futuras excavaciones proporcionarán nuevos ejemplos de estas piezas, documentadas en otros puntos del Mediterráneo donde parecen comenzar

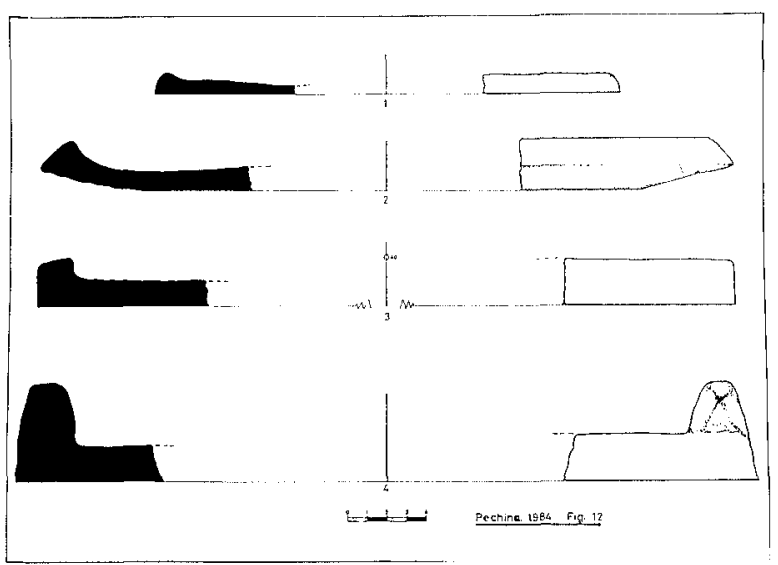

Fig. 12.- Platos-tapadera de Pechina (según ACIEN, 1986, Fig. 12).

a ser muy significativas a partir de la alta edad media.

Estos platos de pan pueden relacionarse morfológica y funcionalmente con los «testi da fuoco» o «testelli» característicos del norte y centro de Italia a lo largo de todo el medievo (CABONA, MANNONI y PIZZOLO, 1982, 347). Se trata de platos para cocer hogazas de harina de castaña o gachas farináceas y cuyo uso en algunas regiones ha pervivido hasta la actualidad. Su origen, también muy antiguo, se relaciona con una modalidad de cocción alternativa al método sub testu estudiado por Frayn; es la cocción de la hogaza sobre una teja o un disco de cerámica, que aparece ya desde la edad del Bronce (WHITEHOUSE, 1978). Generalmente son tipos discoidales sin apenas bordes, pero en contextos como los de Montearrenti, en Siena, fechables a fines del siglo XIII, conviven con formas de paredes altas que documentan la fase de transición hacia las cazuelas propiamente dichas (RONCAGLIA et alii, 1986, 268-71).

De esta forma, ambas piezas cerámicas, hornillo (tannūr) y plato (tâabaq), se vinculan a la fabricación de uno de los alimentos básicos del medievo en sus aspectos tecnológicos más elementales. El fenómeno de los sistemas de cocción transportables, que no generan una estructura constructiva estable ni requieren un lugar definido dentro del espacio doméstico, sea público o privado, nos remite preferentemente a formas de vida de tipo rural. Su aparición como formas significativas en contextos altomedievales - bien de tradición tardorromana como parece ser el caso de los platos de pan, bien de origen norteafricano y oriental en el de los horni- 
llos de atanor - debe relacionarse con las profundas transformaciones económicas que se producen en ambas riberas del Mediterráneo occidental a partir de los siglos V y VI con la crisis del sistema de intercambio a gran escala. Quizá un reflejo de estos cambios se deba buscar en las transformaciones de los hábitos alimenticios y culinarios, privados ahora de los productos - tanto de servicio como de consumo- importados. El sistema de producción y distribución se regionaliza: los alimentos consumidos se deberán limitar a los producidos por la comunidad o a los procedentes de un intercambio de escala local o comarcal; sin olvidar la importancia que en una sociedad «descomercializada» -en palabras de Helen Petterson $(1985,101)$ - cobra la explotación inteligente de los recursos naturales, en suma, la contribución del monte, el marjal o el inculto al consumo alimenticio mediante la recolección de todo tipo de nutrientes espontáneos, constatado en diversos asentamientos altomedievales (GUTIERREZ, 1989). El uso de frutos secos y plantas silvestres para la obtención de sucedáneos farináceos ilustra esta necesidad.

Sin embargo, si bien esta necesidad es común a ambas riberas del Mediterráneo occidental, las soluciones tecnológicas que se adoptan son diversas, atendiendo a tradiciones diferenciadas. Así, en el caso de Al-Andalus, vinculado al ámbito cultural islámico a partir del siglo VIII, se introduce un tipo de horno portátil —el tannūr - que no figura entre las tradiciones grecorromanas de panificación. Por el contrario obedece a prototipos de tradición semita, utilizados desde la protohistoria en el Próximo Oriente y la costa norteafricana y generalizado con la conquista islámica. La difusión de este tipo de hornillo no alcanza a los territorios no musulmanes del Mediterráneo occidental, donde en el alto medievo existen otros útiles de cocción herederos del clibanus o testum-, también portátiles y ligados a la transformación y conservación de productos alimenticios secundarios, pero fruto de una tradición diversa. La bandeja de pan, por el contrario, es un recipiente utilizado en ambos ámbitos y cuyo uso se atestigua en la Península Ibérica con anterioridad a la llegada de los musulmanes.

En cualquier caso, una vez que estas formas ocupan su lugar en el repertorio funcional, su uso se generaliza y se mantiene a lo largo del medievo islámico - al menos en algunas zonas del Sharq AlAndalus - en contextos rurales, ya que en los ambientes urbanos la tecnología de la panificación de- be estar dominada por el horno de obra (furn) como aparato de cocción (no obstante, no existen demasiados datos arqueológicos sobre hornos de pan procedentes de excavaciones urbanas que confirmen esta suposición). No hay que olvidar, tampoco, que ambos tipos y particularmente el hornillo, se mantienen en uso como producciones domésticas (COLL, MARTI, PASCUAL, 1988, 27 en época bajomedieval, para paulatinamente ir dejando de aparecer en los registros cerámicos.

\section{BIBLIOGRAFÍA}

ACIEN ALMANSA, M. 1986: «Cerámica a torno lento en Bezmiliana. Cronología, tipos y difusión». III Congreso de Arqueología Medieval Española (Huesca, 1985), Zaragoza, Vol. IV, 243-267.

AUDOUZE, F. 1989: «Foyers et structures de combustion domestiques aux âges des métaux». Nature et fonction des foyers prehistoriques. (Actes du coloque de Nemours 1987). Memoires du Musée de Préhistoire d'Ile de France, 2, 327-334.

AZUAR RUIZ, R. 1985: «Primera noticia de los trabajos arqueológicos realizados en el yacimiento de las dunas de Guardamar del Segura (Alicante). Una posible rábita de época califal». Sharq Al-Andalus, vol. 2, 125-136.

- 1986: «Una mezquita califal en las dunas de Guardamar del Segura (Alicante)». I Congreso de Arqueologia Medieval Española (Huesca, 1985), vol. III, 505-520, Zaragoza.

- 1987: «El posible al-monastir de las dunas de Guardamar del Segura (Alicante)». V Jornades d'Estudis Històrics locals (Palma de Mallorca, 1985), 265-309, Palma de Mallorca.

- 1988: «Castillo del Río, Aspe. Vinalopó Mitjà» Memòries Arqueòlogiques a la Comunitat Valenciana. 1984-85. Generalitat Valenciana. Conselleria de Cultura, Educació i Ciencia. Valencia, 38-39.

- 1989: Denia islámica. Arqueologia y poblamiento. Instituto de Cultura «Juan Gil-Albert». Diputación Provincial de Alicante. Alicante.

AZUAR, R. et alii. 1989: La rábita califal de las Dunas de Guardamar (Alicante). Cerámica. Epigrafía. Fauna. Malacofauna. Memorias del Museo Arqueológico Provincial. Diputación Provincial de Alicante. Alicante.

BAZZANA, A. 1979: «Céramiques médiévales: les méthodes de la description analytique apliquées aux productions de l'Espagne orientale». Melanges de la Casa Velázquez, $\mathrm{XV}$, 135-185.

- 1980: «Céramiques médiévales: les méthodes de la descripcion analytique apliquée apliquées aux productions de l'Espagne orientale. II. Les poteries décorées. Chronologie des productions médiévales». Melanges de la Casa Velázquez, XVI, 57-95.

BOLENS, L. 1980: «Pain quotidien et pains de disette dans l'Espagna musulmane». Annales E.S.C., n. ${ }^{\circ}$ 3-5, Mai-Août. $462-476$. 
BOSCH FERRO, C. y CHINCHILLA GOMEZ, M. 1987: «Formas cerámicas auxiliares: anafes, arcaduces y otras». II Congreso de Arqueología Medieval Española (Madrid, 1987), Madrid, Vol. II, 491-500.

BROGIOLO, G.P., GELICHI, S. 1986: «La ceramica grezza medievale nella pianura padana». La ceramica medievale nel Mediterraneo occidentale (Siena-Faenza, 1984). Firenze 293-317.

CABONA, D. MANNONI, T. PIZZOLO, O. 1982: «Gli scavi nel complesso medievale di Filattiera in Lunigiana. 1: la collina di San Giorgio». Archeologia Medievale, IX, 331-58.

CATALA FERRER, E. 1989: «Anafes, candiles y braseros de Qustantaniya». Mare de Deu del Miracle, Cocentina.

CINTAS, P. 1962: «Tābūn» Oriens Antiquus, 1, 233-244.

COLL, J. 1988-89: «Cerámica i cambio cultural» Afers, 7, 125-169.

COLL, J.; MARTI, J.; PASCUAL, J.; 1988: Cerámica y cambio cultural. El tránsito de la Valencia islámica a la cristiana. Ministerio de Cultura. Madrid.

CORTES, L. L. 1954: «La alfarería en Pereruela (Zamora)». Zephyrus, V, 2-3 mayo-diciembre. Salamanca.

COUSIN, F. 1989: «Les foyers culinaires actuels au Rajasthan (Inde) $):$ Nature et fonction des foyers prehistoriques. (Actes du colloque de Nemours, 1987). Memoires du Musée de Préhistoire d'lle de France, 2, 87-100.

CUBBERLEY, A. L.; LLOYD, J. A.; ROBERTS, P. C. 1988: «Testa and Clibani: the baking covers of classical Italy», PAPERS OF THE BRITISH SCHOOL AT ROME, Vol. LVI, 98-119.

LLOYD DAREMBERG, CH.; SAGLIO. E. 1969. Dictionnarie des Antiquites Grecques et Romaines. Graz. Repr. anas. 1877-1919; s. v. Pistor, Clibanus y Purnus.

ENCYCLOPÉDIE BERBĖRE, 1987: S. V. «A164 Alimentation». Vol. IV. 472-529. Aix-en-Provence.

FRAYN, J. 1978: «Home-baking in Roman Itay». ANTIQUITY, Vol. LII, N. ${ }^{\circ} 204,28-33$.

FORBES, R. J. 1966: Studies in Ancient Technology, Vol. VI. "Heat an Heating. Refrigeration. Light». Leiden, E. J. Brill.

GALLAY, A. 1989: «Vivre autour d'un feu. Recherche d'une problématique d'analyse archéologique». Nature et fonction des foyers prehistoriques. (Actes du colloque de Nemours 1987). Memoires du Musée de Préhistoire d'lle de France, 2. 101-122.

GARCIA SANCHEZ, E. 1988: «Aspectos dietéticos de la alimentación en Al-Andalus». Historia y Cultura del Islam español (Curso de Conferencias 1986-7). Escuela de Estudios Arabes. C.S.I.C. Granada. 43-65.

GUTIERREZ LLORET, S. 1986: «Cerámicas comunes altomedievales: contribución al estudio del tránsito de la Antigüedad tardía al mundo paleoislámico en las comarcas meridionales del País Valenciano". LUCENTUM, V. Anales de la Universidad de Alicante. Prehistoria, Arqueología e Historia Antigua. 147-169.

- 1987: «Avance para una tipología de las formas modeladas a mano del Ribat califal de Guardamar del Segura (Alicante)". II C.A.M.E. (Madrid, 1987), II, 689-740.

- 1988: Cerámica común paleoandalusí del sur de Alicante (siglos $V I I-X)$. Alicante.

- 1989: «Espacio y poblamiento paleoandalusi en el sur de Alicante: origen y distribución". III Congreso de Arqueología Medieval Española (Oviedo, 1989) (en prensa).

HODGES, R., PATTERSON, H. 1986: «San Vicenzo al Vol- turno and the origins of the medieval pottery industry in Italy». La cerámica medievale nel Mediterraneo occidentale (Siena-Faenza, 1984). Firenze. 13-27.

IBN AL-AWWAM: Libro de agricultura. Editor y traductor: J.A. BANQUERI, Madrid, 1802 (Edición facsímil, 1988. Ministerio de Agricultura, Pesca y Alimentación.

IBN RAZIN AL-TUYIBI: Fadalat al-jiwan fi tayybat al.ta am wa al-alwan. Editor: M. B. CHEKROUN: La cuisine andalou-marrocaine an XIII siècle. Rabat, 1982.

ISIDORO DE SEVILLA. Etimologias. OROZ RETA, J. y MARCOS CASQUERO, M. (Ed. y trad.), 1983. Edición bilingüe. 2 vols. Biblioteca de Autores Cristianos.

IZQUIERDO BENITO, R. 1979: «Excavaciones en la ciudad hispano-musulmana de Vascos (Navalmoralejo, Toledo). Campañas 1975-78». Noticiario Arqueológico Hispánico 7, 248-392.

- 1983: «Excavaciones en la ciudad hispano-musulmana de Vascos (Navalmoralejo, Toledo). Campañas 1979-80». Noticiario Arqueológico Hispánico, 16, 289-380.

IBARRA, P. 1926: Elche, materiales para su historia. Cuenca.

LAIZ REVERTE, M. ${ }^{a}$ D.; RUIZ VALDERAS, E. 1988: «Cerámicas de cocina en los siglos V-VII en Cartagena $(\mathrm{C} /$. Orcel-D. Gil)». Antigüedad y Cristianismo, V. (en prensa).

LANCEL, S. 1979: Byrsa I. Rapports préliminaires des fouilles (1974-1976). Ecole Française de Rome. Roma.

LANCEL, S. 1982: Byrsa II. Rapports préliminaires des fouilles (1977-1978). Ecole Française de Rome. Roma.

LEVI-PROVENÇAL, E. 1987: España musulmana hasta la caída del Califato de Córdoba (711-1031 de J.C.). Vol. V. Instituciones y vida social e intelectual. 5. ${ }^{a}$ edición. Madrid.

LLOBREGAT CONESA, E. 1989a: «Els cereals al món mediterrani de l'època classica». Del gra al pa. El cicle dels cereals. València, Generalitat Valenciana. 39-42.

- 1989b: «ISIDORUS HISPALENSIS, Etymologiarum siue originum, $\mathrm{XX}, \mathrm{ii}, 7 ; 15-19$. Intento de comentario». Homenaje al Dr. M. Ponsich (en prensa).

MANACORDA et alii, 1986: «La ceramica medioevale di Roma nella stratigrafia della Crypa Balbi». La cerámica medievale nel Mediterraneo occidentale (Siena-Faenza, 1984). Firenze. 511-545.

MESQUIDA, M.; AMIGUES, F. 1986: «Hallazgo de un "pozo" de cerámica en el casco antiguo de Paterna». I Congreso de Arqueología Medieval Española (Huesca, 1985), Zaragoza, Vol. V, 541-557.

NAVARRO POVEDA, C. 1988: Petrer islámico. Alicante.

NOBILE, I. et alli, 1988: «Scavi di Monte Barro. Commune di Galbiate, Como (1986-87)» Archeologia medievale, XV, 177-252.

PATTERSON, H. 1985: «The late roman and early medieval pottery from Molise») en HODGES, R y MITCHELL, J. San Vicenzo al Volturno. The archaeology, art and territory an early medieval monastery. B.A.R. (Internat. Ser), 252.

PEACOCK, D.P.S. 1982: Pottery in the roman world. An etnoarcheological approach. London.

PUERTAS TRICAS, R. 1986-87: «Los hallazgos arqueológicos de torreblanca del Sol (Fuengirola)». Mainake, VIII-IX. 145201. Málaga.

QUESADA SANZ, F. LOPEZ GRANDE, M. ${ }^{a}$ J. 1988: «Talleres y producciones cerámicas actuales en Egipto: un estudio etnoarqueológico en Heracleópolis Magna». Boletín de la Asociación Española de Orientalistas. 325-355. Madrid.

RONCAGLIA, G. 1986: «La ceramica grezza medievale in un 
insediamento del contado senese» en FRANCOVICH et alii: Il progetto Montearrenti (SI). Relazione preliminare, 1985. Archeologia medievale, XIII, 257-320.

ROSENBERGER, B. 1980: «Cultures complémentaires et nourritures de substitution au Marroc (XVe-XVIIIe siècle)». Annales E.S.C., N. ${ }^{\circ}$ 3-5, Mai-Août. 477-503.

ROSSELLO, BORDOY, G. 1978: Ensayo de sistematización de la cerámica árabe en Mallorca. Palma de Mallorca.

- 1990: «Precisiones sobre terminología cerámica andalusí» I Coloquio Hispano-Italiano de Arqueología Medieval. Granada (en prensa).

SHERBY, O. D.; WADSWORTH, J. 1985: «Aceros de Damasco». Investigación y ciencia. Abril. 76-82.
SOLER, M. ${ }^{a}$ P. 1988: Historia de la cerámica valenciana. Vol II: Valencia.

STAFFA, A. R. 1986: «Ricognizioni nel territorio di Atri: problemi di una presenza volturnese». Archeologia Medieva$l e$, XIII, 437-60. Firenze.

TURINA GOMEZ, A. y RETUERCE VELASCO, M. 1987: «Arqueología más reciente» 130 años de Arqueología Madrileña. Madrid.

TLATLI, S. E. 1978: le Carthage Punique. París.

VEGAS, M. 1973: Cerámica común romana del Mediterráneo occidental. Instituto de Arqueología y Prehistoria de la Universidad de Barcelona.

WHITEHOUSE, D. 1978: «Home-baking in Roman Italy: a footnote». ANTIQUITY, Vol. LII, N. ${ }^{\circ} 205,146-47$. 